Volume 02 Nomor 02, Desember 2020 Page 9-14

Incrementapedia: Jurnal Pendidikan Anak Usia Dini

Program Studi PG-PAUD Fakultas Pedagogik dan Psikologi

Universitas PGRI Adi Buana Surabaya

http://jurnal.unipasby.ac.id/index.php/incrementapedia

e-ISSN: 2686-3146

\title{
PELAKSANAAN KEGIATAN KELOMPOK KERJA KEPALA TK (K3TK) DI KECAMATAN SEDATI SEBAGAI UPAYA MENINGKATKAN KEMAMPUAN KEPALA TAMAN KANAK-KANAK DALAM PENGELOLAAN ADMINISTRASI SEKOLAH SEMESTER 2 TAHUN PELAJARAN 2017/2018
}

\author{
Siti Hamidah \\ Pengawas Taman Kanak-Kanak Kecamatan Sedati Kabupaten Sudoarjo \\ Email: sthmdh05@gmail.com
}

\begin{abstract}
The problem in this study is the low ability of the Kindergarten Head in managing school administration. This was proven by the incomplete management documents of the school administration by 30 Kindergarten Heads in Sedati District. The purpose of the study was to improve the ability of the Kindergarten Head in the Sedati District in the management of school administration. The research subjects were 30 Kindergarten Heads in Sedati District. This research was conducted in two cycles. The data collection method uses observation and documentation techniques. Data validation used in this action research is democratic, process and dialogic validation. Data analysis was performed by comparing results on initial conditions, results of cycle I, results of cycle II. The results showed that in the initial conditions 30 Kindergarten Heads were declared unable to manage administration well or $0 \%$ with an average rating of 40.29, increasing to 12 Kindergarten Heads or $40 \%$ in the first cycle with an average yield of 58.75 and $100 \%$ in the second cycle with the acquisition of an average value of 77.89. The explanation of the criteria for the value of the initial conditions is less, increasing to enough and good in the last cycle. looking at the data obtained from the results of research in this school ction research activity, it can be concluded that the K3TK activities in the Patronage of Sedati Subdistrict conducted by school supervisors for 30 Kindergarten Heads were declared successful in increasing the ability of the Kindergarten Head in managing school administration.
\end{abstract}

Keywords: K3TK, kindergarden Head's ability, school administration

\section{PENDAHULUAN}

Kepala TK memang berperan sangat penting dalam perkembangan sekolah. Oleh karena itu, ia harus memiliki jiwa kepemimpinan untuk mengatur para guru, pegawai tata usaha, dan pegawai sekolah lainnya. Dalam melaksanakan fungsi kepemimpinannya Kepala TK harus melakukan pengelolaan dan pembinaan sekolah melalui kegiatan administrasi, manajemen dan kepemimpinan yang sangat tergantung pada kemampuannya. Peran Kepala TK sebagai administrator, memiliki dua tugas utama. Pertama, sebagai pengendali struktur organisasi, yaitu mengendalikan bagaimana cara pelaporan, dengan siapa tugas tersebut harus dikerjakan dan dengan siapa beriteraksi dalam megerjakan tugas tersebut. Kedua, melaksanakan administrasi substansi yang mencakup administrasi kurikulum, kesiswaan, personalia, keuangan, sarana hubungan dengan masyarakat, dan administrasi umum.

Di dalam Peraturan Menteri Pendidikan Nasional Nomor 13 tahun 2007 tentang standar Kepala TK harus memilki kualifikasi dan kompetensi yang ditentukan, baik kompetensi dimensi kepribadian, kompetensi dimensi manajerial, kompetensi dimensi kewirausahaan, kompetensi dimensi supervisi dan kompetensi dimensi sosial. Oleh karena itu maka Kepala TK untuk terus dibina dan dikembangkan oleh pengawas sekolah agar dapat memilki standar kompetensi Kepala TK yang ditentukan.

Hasil pengamatan pengawas sekolah terhadap kemampuan Kepala TK di wilayah binaan di Kecamatan Sedati menunjukkan 
bahwa kemampuan Kepala TK dalam pengelolaan administrasi sekolah masih rendah. Padahal Kepala TK memiliki tugas dan tanggung jawab yang besar dalam pengelolaan administrasi sekolah. Realita di lapangan menunjukkan bahwa Kepala TK "enggan” untuk melakukan tugas dan tanggung jawab dalam pengelolaan administrasi sekolah karena ketidaktahuan dan kurangnya informasi tentang tata cara dan pengelolaan terhadap administrasi sekolah yang baik dan benar.

Dalam rangka memperlancar programprogram pemerintah dan untuk mencapai tujuan negara yang terdapat dalam pembukaan UUD 1945 alinea ke-empat yaitu mencerdaskan kehidupan bangsa, di tingkat kecamatan diadakan pembentukan gugus sekolah. Lembaga TK yang ada di Kecamatan Sedati ini terbagi menjadi 4 Gugus yang saling berdekatan. Pada setiap gugus ada TK inti terdapat KKG (Kelompok Kerja Guru), PKG (Pusat Kegiatan Guru) dan K3TK (Kelompok Kerja Kepala TK) yang merupakan wadah pembinaan profesional (Depdikbud, 1996/1997:4).

K3TK merupakan kelompok kerja bagi Kepala TK dasar, diharapkan dapat memberikan kontribusi nyata serta dapat mendukung secara optimum peningkatan kemampuan professional Kepala TK dalam mengelola sekolah. Terkait hal tersebut Kepala TK perlu adanya motivasi secara terus menerus untuk senantiasa meningkatkan profesionalismenya. Prinsip kerja K3TK yaitu K3TK merupakan lembaga yang mandiri, tidak mempunyai struktur organisasi yang hirarkis, birokratik dan saling ketergantungan, tetapi merupakan wadah berkumpulnya kelompok kerja Kepala TK. Oleh karena itu K3TK yang merupakan kelompok kerja Kepala TK dipandang sangat strategis untuk meningkatkan mutu profesionalisme Kepala TK khususnya dalam pengelolaan administrasi sekolah.

Berdasarkan kenyataan tersebut, maka upaya untuk meningkatkan kompetensi Kepala TK dilakukan melalui berbagai strategi. Salah satu strategi untuk menjangkau seluruh Kepala TK dalam waktu yang cukup singkat adalah memanfaatkan forum Kelompok Kerja Kepala TK (K3TK) sebagai wahana belajar bersama. Kepala TK dalam forum tersebut dapat saling berbagi pengetahuan dan pengalaman guna bersama-sama meningkatkan kompetensi dan kinerjanya dalam suasana kesejawatan yang akrab.

\section{METODE PENELITIAN}

Metode yang digunakan dalam penelitian ini adalah penelitian tindakan (action research) dalam upaya meningkatkan kemampuan 30 Kepala TK di Kecamatan Sedati dalam pengelolaan administrasi sekolah. Pendekatan yang digunakan dalam penelitian ini adalah adalah pendekatan deskriptif kualitatif.

Penelitian ini mengambil bentuk penelitian tindakan sekolah (PTS) yaitu peningkatan kemampuan Kepala TK dalam pengelolaan administrasi sekolah, yang terdiri dari 2 siklus dan masing masing siklus terdiri dari 4 tahap yaitu: (1) tahap perencanaan program tindakan, (2) pelaksanaan program tindakan, pengamatan program, (4) refleksi.

Teknik pengumpulan data dalam penelitian ini menggunakan beberapa metode diantaranya observasi dan dokumentasi.

\section{HASIL DAN PEMBAHASAN \\ a. Deskripsi Data \\ 1) Kondisi Awal Siklus}

Kenyataan di lapangan para Kepala TK di Kecamatan Sedati Kabupaten Sidoarjo yang terdiri dari 30 sekolah masih belum mampu menyusun administrasi sekolah dengan baik dan benar sesuai dengan aturan yang berlaku. Hal ini tentunya menimbulkan keprihatinan tersendiri bagi peneliti yang kebetulan bertugas sebagai pengawas pembina di wilayah tersebut. Seperti diketahui bersama bahwa Kepala TK bertindak sebagai administratror pendidikan penanggung jawab terhadap kelancaran pelaksanaan pendidikan pengajaran disekolahnya oleh karena itu, untuk dapat melaksanakan tugasnya dengan baik, Kepala TK hendaknya memahami, menguasai dan mampu melaksanakan fungsi sebagai administrator pendidikan.

Kemampuan Kepala TK di Kecamatan Sedati Kabupaten Sidoarjo dalam menyusun administrasi sekolah masih belum tuntas/ belum maksimal. Hal tersebut ditunjukkan dari hasil observasi pada kondisi awal menunjukkan semua Kepala TK masih belum mampu menyusun administrasi sekolah secara maksimal dengan dibuktikan dari hasil penilaian pada kondisi awal dari 30 Kepala TK, 18 Kepala TK dalam kategori kurang dan 12 Kepala TK dalam kategori nilai cukup.

Berdasarkan hal itu, maka salah satu upaya yang dapat dijadikan alternatif untuk meningkatkan kemampuan Kepala TK khususnya di Kecamatan Sedati dalam menyusun administrasi sekolah yaitu dengan melaksanakan kegiatan pembinaan melalui 
pelaksanaan K3TK sebagai pemecahan masalah yang diharapkan yaitu meningkatnya Kepala TK di Kecamatan Sedati dalam menyusun administrasi sekolah.

\section{2) Pelaksanaan Siklus Pertama}

Setelah dilakukan kegiatan pembinaan melalui pelaksanaan K3TK diperoleh hasil bahwa pada pelaksanaan kegiatan siklus pertama bahwa 12 orang Kepala TK atau 40\% dinyatakan meningkat kemampuannya dalam menyusun administrasi sekolah karena masuk dalam kategori BAIK, dan sisanya sebanyak 18 orang Kepala TK atau $60 \%$ dinyatakan belum tuntas secara maksimal kemampuannya dalam menyusun administrasi sekolah karena baru memenuhi kriteria hasil penilaian dalam kategori cukup, dan secara klasikal nilai rata-rata kemampuan menyusun administrasi sekolah baru mencapai angka 58,75 dan masuk dalam kriteria CUKUP.

Dari analisis data di atas maka dapat ditarik kesimpulan bahwa pelaksanaan penelitian tindakan sekolah dengan menerapkan pola pembinaan K3TK bagi Kepala TK di Kecamatan Sedati dinyatakan belum berhasil karena belum memenuhi kriteria keberhasilan yang telah ditetapkan yaitu minimal $85 \%$ dari jumlah Kepala TK mendapat rentang nilai minimal BAIK.

Berdasarkan hasil observasi pelaksanaan tindakan perbaikan pada siklus kesatu masih ada beberapa hal yang perlu diperbaiki berdasarkan hasil wawancara dan observasi pada saat kegiatan K3TK maupun hasil pelaksanaan kegiatan presentasi, yaitu: (1) Masih adanya kesulitan bagi beberapa orang Kepala TK dalam menyusun administrasi sekolah, (2) Ketidakpahaman sebagian Kepala TK dalam mengidentifikasi indikator-indikator dalam menyusun administrasi sekolah sehingga terjadi banyak kesalahan pada pengisian terhadap masing-masing indikator tersebut, dan (3) Ketidaksiapan para Kepala TK dalam mempersiapkan perangkat administrasi sekolah.

Dengan masih terdapatnya hal-hal tersebut di atas, maka diperlukan langkah perbaikan selanjutnya. Dengan kata lain perlu siklus kedua sehingga perbaikannya optimal dan diharapkan kemampuan para Kepala TK di Kecamatan Sedati dalam menyusun administrasi sekolah dapat meningkat dan memenuhi kriteria keberhasilan yang telah ditentukan.

\section{3) Pelaksanaan Siklus Kedua}

Setelah dilakukan kegiatan pembinaan melalui pelaksanaan K3TK diperoleh hasil bahwa pada pelaksanaan kegiatan siklus kedua semua Kepala TK terdiri dari 18 orang Kepala TK atau $60 \%$ mendapat kriteria SANGAT BAIK dan 12 orang Kepala TK atau 40\% mendapat kriteria nilai BAIK dalam mengikuti kegiatan K3TK penyusunan administrasi sekolah, sehingga dapat disimpulkan bahwa semua Kepala TK tersebut dinyatakan meningkat kemampuannya dalam menyusun administrasi sekolah karena telah memenuhi kriteria keberhasilan penelitian yaitu minimal mendapat nilai dalam kategori BAIK.

Berdasarkan hasil observasi pelaksanaan tindakan perbaikan pada siklus kedua menunjukkan hasil diantaranya sebagai berikut: (1) Semua aspek penilaian telah memenuhi kriteria dan indikator keberhasilan yang telah ditetapkan, sehingga semua Kepala TK yang mengikuti kegiatan K3TK dinyatakan mampu menyusun administrasi sekolah yang telah dibuatnya dengan baik, dan (2) Peningkatan kemampuan dapat tercapai dengan baik secara maksimal disebabkan oleh berbagai faktor, diantaranya kesiapan alat dan bahan yang dibawa oleh para Kepala TK, keseriusan Kepala TK dalam mengikuti kegiatan K3TK dan motivasi dan minat para Kepala TK yang besar untuk dapat menguasai materi K3TK khususnya penyusunan administrasi sekolah dengan baik dan benar.

\section{b. Hasil Penelitian \\ 1) Tindakan Siklus Pertama}

Pada kondisi awal belum ada kepala yang dinyatakan mampu menyusun administrasi sekolah dengan benar. Setelah dilaksanakan perbaikan dengan penerapan pola pembinaan melalui pelaksanaan kegiatan K3TK pada pelaksanaan siklus pertama terdapat 12 orang Kepala TK yang dinyatakan sudah mampu menyusun administrasi sekolah yang baik, sedangkan sisanya 18 orang Kepala TK masih belum mampu menyusun administrasi sekolah dengan baik dan benar walaupun telah mengalami peningkatan kemampuan dibandingkan pada kondisi awal. Penjelasan mengenai penilaian kemampuan Kepala TK dalam menyusun administrasi sekolah secara klasikal menunjukkan angka 58,75 dan berada dalam kriteria cukup.

\section{2) Tindakan Siklus Kedua}

Pada pelaksanaan siklus kedua semua Kepala TK di Sekolah Binaan Kecamatan Sedati yang terdiri dari 30 orang Kepala TK dinyatakan telah mampu menyusun administrasi sekolah dengan baik, dengan penjelasan 18 orang Kepala 
TK dalam kriteria sangat baik dan 12 Kepala TK dalam kriteria baik. Penjelasan mengenai nilai rata-rata klasikal menunjukkan angka 77,89 dengan kriteria baik.

Dari hasil tersebut dapat disimpulkan bahwa pada pelaksanaan siklus kedua ini semua Kepala TK dinyatakan telah mampu menyusun administrasi sekolah dengan baik, sehingga proses perbaikan yang dilakukan dengan pelaksanaan penelitian tindakan sekolah dinyatakan selesai dan tuntas pada siklus kedua. Untuk memperjelas peningkatan kemampuan Kepala TK dalam menyusun administrasi sekolah setelah dilakukan pembinaan dengan pelaksanaan kegiatan K3TK di Sekolah Binaan Kecamatan Sedati sebagaimana dijelaskan pada grafik di bawah ini.

\section{3) Tindakan Perbaikan Antar Siklus}

Pada setiap siklus yang dilaksanakan terbukti dapat meningkatkan kemampuan Kepala TK dalam menyusun administrasi sekolah Hal tersebut dibuktikan dengan meningkatnya kemampuan kepala pada setiap siklusnya berdasarkan nilai rata-rata yang diperoleh serta tingkat ketuntasannya. Pada kondisi awal nilai yang diperoleh sebesar 45,83 dan masuk dalam kategori Cukup, dan pada siklus pertama menjadi 58,75 dan masuk kategori cukup, sedangkan pada siklus kedua mencapai nilai sebesar 77,89 dan semua Kepala TK masuk dalam kategori baik dan sangat baik. Dari hasil tersebut dapat disimpulkan bahwa pada pelaksanaan siklus kedua semua Kepala TK dinyatakan mampu menyusun administrasi sekolah dengan baik karena nilai yang dihasilkan dan kategori nilai telah memenuhi batasan indikator keberhasilan, yaitu minimal dalam kategori BAIK.

\section{c. Pembahasan}

Berdasarkan analisis dan pembahasan seperti yang telah dipaparkan pada bagian sebelumnya, maka dapat disimpulkan bahwa terjadi peningkatan kemampuan Kepala TK dengan pola pembinaan $\mathrm{K} 3 \mathrm{TK}$, dalam menyusun administrasi sekolah di sekolah binaan di Sekolah Binaan Kecamatan Sedati dari kondisi awal, siklus I ke siklus II pada masing-masing aspek dengan target ketercapaian sesuai dengan kriteria yang ditetapkan. Dengan demikian dapat disimpulkan bahwa melalui K3TK dapat meningkatkan kemampuan Kepala TK dalam menyusun administrasi sekolah.

Keberhasilan tindakan ini disebabkan oleh pemahaman Kepala TK di wilayah binaan Kecamatan Sedati secara menyeluruh tentang penyusunan administrasi sekolah sangat baik. Dengan pemahaman yang baik, maka kemampuan Kepala TK di wilayah binaan Kecamatan Sedati secara menyeluruh tentang penyusunan administrasi sekolah diharapkan juga membaik. Pengoptimalan pemahaman Kepala TK terhadap penyusunan penyusunan administrasi sekolah melalui pola pembinaan dalam bentuk penyelenggaraan K3TK menunjuk pada metode kooperatif konsultatif dimana diharapkan para Kepala TK dapat berdiskusi, bekerja sama dan berkonsultasi secara aktif. Aktifitas ini akan sangat membantu mereka dalam memahami penyusunan penyusunan administrasi sekolah yang pada akhirnya nanti diharapkan para Kepala TK di wilayah binaan mampu menyusun administrasi sekolah sesuai dengan potensi dan kondisi nyata yang ada di sekolahnya masing-masing.

Dalam kaitannya dengan pembinaan melalui K3TK, K3TK atau sering disebut dengan K3TK merupakan salah satu wadah atau tempat kegiatan yang dapat melakukan peningkatan kemampuan dan keterampilan profesional Kepala TK dasar dalam rangka meningkatkan manajemen mutu pendidikan. K3TK adalah suatu perkumpulan para Kepala TK yang melakukan berbagai kegiatan sebagai wadah untuk menambah wawasan, pengetahuan, keterampilan, dan pengalaman Kepala TK dalam memecahkan berbagai masalah yang dihadapi dalam melakukan pengelolaan organisasi sekolah secara keseluruhan dan memberikan pembinaan profesional kapada guru dalam rangka meningkatkan kualitas pelaksanaan proses belajar mengajar di sekolah.

Tujuan K3TK menurut (Sri Banun Muslim, 2010: 95), pada dasarnya adalah untuk meningkatkan kemampuan, pengetahuan, keterampilan, dan pengalaman para Kepala TK dalam melaksanakan tugas dan tanggungjawabnya sebagai pemimpin pendidikan terutama sekali dalam masalah manajemen sekolah dan manajemen proses belajar mengajar yang dilakukan guru di sekolah masing-masing. Menurut Sjarif(1995:18) K3TK mempunyai fungsi untuk meningkatkan mutu, kemampuan, dan keterampilan kepemimpinan Kepala TK serta keterampilan manejerialnya dan keterampilan dalam: (a) memecahkan masalah yang belum terpecahkan oleh guru, (b) memecahkan masalah dari temuan hasil supervisi, (3) mengkoordinasikan Kepala TK untuk merumuskan berbagai kiat tentang kepemimpinan dan menejeman, dan (d) 
menyusun Rencana Anggaran Pendapatan dan Belanja Taman Kanak-kanak (RAPBTK). Menurut Muslim (2010:104) empat fungsi dari K3TK ini yaitu; (1) K3TK merupakan sebuah wadah untuk ikut memecahkan masalah yang belum terpecahkan oleh guru pada pertemuan KKG, (2) K3TK merupakan wadah untuk memecahkan masalah menajemen sekolah berdesarkan temuan-temuan hasil supervisi di sekolah, (3) K3TK merupakan sebuah lembaga atau badan sederhana yang mampu mengkoordinir Kepala TK dalam satu gugus, untuk melahirkan kiat-kiat kepemimpinan sekolah, serta (4) K3TK sebagai wadah untuk menghasilkan gagasan-gagasan baru meningkatkan mutu pendidikan.

Dengan pola pembinaan K3TK ini diharapkan agar para Kepala TK di wilayah binaan Kecamatan Sedati memperoleh dasar yang kuat untuk lebih memahami penyusunan administrasi sekolah secara menyeluruh sebelum melaksanakan penyusunan administrasi sekolah di sekolahnya dengan baik.

Pola pembinaan melalui pelaksanaan kegiatan K3TK khususnya dalam penyusunan administrasi sekolah telah memberikan konstribusi tersendiri untuk pengembangan dan keprofesionalismean seorang Kepala TK dalam melaksanakan tugasnya dan memajukan satuan pendidikan yang mereka pimpin ke arah yang lebih baik sesuai dengan apa yang dicitacitakannya. Melalui K3TK Kepala TK selalu melakukan pembinaan dalam pengembangan dan peningkatan mutu pendidikan di sekolah, mampu menjalin kerjasama yang bermanfaat untuk mengembangkan mutu pendidikan sehingga tercapainya tujuan pendidikan yang telah ditetapkan, dan mampu bertukar pikiran dengan memberikan bimbingan, arahan, dan didikan kepada guru yang bermasalah untuk meningkatkan kualitas dan cara-cara mengajar pada saat proses belajar mengajar berlangsung Melalui K3TK, seorang pengawas diharapkan mampu memberikan atau menghadirkan tutorial yang berkualitas pada setiap pertemuan K3TK, hal ini dimaksudkan agar pelaksanaan K3TK tidak monoton dan membosankan.

Dari paparan di atas, menunjukkan bahwa peningkatan kemampuan Kepala TK melalui kegiatan K3TK yang lebih menekankan pada metode kolaboratif konsultatif akan memberikan kesempatan sharing antara satu Kepala TK yang satu dengan Kepala TK yang lain. Dengan demikian, pemahaman dan kemampuan terhadap penyusunan penyusunan administrasi sekolah dapat ditingkatkan baik dalam teoritisnya maupun dalam implementasinya.

\section{Kesimpulan}

Berdasarkan hasil analisis data dan pembahasan yang telah dibahas mengenai pelaksanaan K3TK di Wilayah Binaan Kecamatan Sedati sebagai upaya meningkatkan kemampuan Kepala TK dalam menyusun administrasi sekolah dapat ditarik beberapa kesimpulan bahwa:

1. Model pembinaan peningkatan kemampuan Kepala TK dalam pengelolaan administrasi sekolah dengan pelaksanaan K3TK terbukti mampu meningkatkan kemampuan Kepala TK dalam pengelolaan administrasi sekolah di Wilayah Binaan Kecamatan Sedati, sehingga diperoleh suatu pengalaman baru dalam penyelenggaraan model pembinaan terhadap peningkatan kemampuan Kepala TK dalam pengelolaan administrasi sekolah yaitu dengan pelaksanaan K3TK.

2. Dari kondisi awal, siklus I hingga siklus II disimpulkan bahwa telah terjadi peningkatan kemampuan Kepala TK dalam pengelolaan administrasi sekolah di Wilayah Binaan Kecamatan Sedati. Hasil observasi dan penilaian menunjukkan bahwa terjadi peningkatan kemampuan para Kepala TK secara signifikan setelah dilaksanakan kegiatan pembinaan dengan kegiatan K3TK. Hal tersebut dapat dilihat pada hasil yang diperoleh, yaitu dari kondisi awal sebanyak 30 Kepala TK dinyatakan belum mampu mengelola administrasi dengan baik atau $0 \%$ dengan rata-rata penilaian 40,29, meningkat menjadi 12 Kepala TK atau $40 \%$ pada siklus pertama dengan hasil rata-rata nilai sebesar 58,75 serta $100 \%$ pada siklus kedua dengan perolehan nilai rata-rata sebesar 77,89 . Penjelasan mengenai kriteria nilai dari kondisi awal adalah KURANG, meningkat menjadi CUKUP dan BAIK pada siklus terakhir.

\section{REFERENSI}

Arikunto. S, (1982). Prosedur Penelitian. Jakarta: PT. Bina Aksara.

Edward Sallis. Alih Bahasa Ali riyadi, Ahmad \& Fahrurozi. (2006). Total Quality Management in Education: Manajemen Mutu Pendidikan. Yogyakarta: Irchisod.

Fariadi, Ruslan. (2010). Total Quality Management (TQM) dan Implementasinya 
Dalam Dunia Pendidikan. (online, http://aa-den.blogspot.com/2010/07/totalquality-management-tqm-dan.html).

Husaini Usman, dan Purnama Setiady Akbar. (1995). Pengantar Statistik. Yogyakarta : Bumi Aksara

Kemdiknas. (2010). Pengembangan Pendidikan Budaya dan Karakter Bangsa. Jakarta: Puskur-Balitbang, Kemdiknas

Moleong, J. Lexy. (2008). Metodologi Penelitian Kualitatif. Bandung: Ramaja Rosdakary

Moleong, Lexy J.. (1989). Metodologi Penelitian Kualitatif, Edisi Revisi. Jakarta : Remaja Rosdakarya

Nasution, S.. (1996). Metode Penelitian Naturalistik-Kualitatif. Bandung: Tarsito

Ngalim Purwanto, (2002). Administarasi dan Supervisi Pendidikan, Bandung: PT. Remaja Rosda Karya

Peraturan Pemerintah Nomor 74 Tahun 2008 tentang Guru

Peraturan Menteri Negara Pendayagunaan Aparatur Negara dan Reformasi Birokrasi Nomor 21 Tahun 2010

R. Fred David, (2004). Konsep Manajemen Strategis, Jakarta: PT Indeks

S.P. Malayu Hasibuan, (1995). Manajemen Sumber Daya Manusia, Jakarta: PT Toko Gunung Agung

Sudjana, Nana, dkk. (2011). Buku Kerja Pengawas Sekolah, Cet. Ke -2, Jakarta:

Pusat Pengembangan Tenaga Kependidikan, Badan PSDM dan PMP Kementerian Pendidikan Nasional

Sudjana, Nana. 2012a. Pengawas dan Kepengawasan: Memahami Tugas Pokok, Fungsi, Peran dan Tanggung Jawab Sekolah. Bekasi: Binamitra Publishing.

Sudjana, Nana. 2012b. Supervisi Pendidikan: Konsep dan Aplikasinya bagi Pengawas Sekolah. Bekasi: Binamitra Publishing.

Tjiptono, F \& Diana, A. 1995. Total Quality Management. Yogyakarta: Andi Offset

Usman, Husaini. 2011. Manajemen: Teori, Praktik, dan Riset Pendidikan. Jakarta: Bumi Aksara

Wiles, J \& Bondi, J (2003). Supervision A Guide to Practice. Second-Edition. London:
Charles E. Merrill Publishing Company A Bell \& Hawwel Company.

Yunus, Falah. 2003. Manajemen Peningkatan Mutu Pendidikan. (online, http://www.geocities.ws/guruvalah/Manaj Pening_Mutu_Pend.html). 